Available Online at https://www.nepjol.info/index.php/IJOSH

International Journal of Occupational Safety and Health, Vol. 6 No. 2 (2016) 6 - 12

\title{
Prevalence, job risk factors and coping strategies of Work Related Musculoskeletal Disorders among Physiotherapists
}

\section{Saravanan Prerana', Bachelor of Physiotherapy, Murugan Saravanan², Masters in Sports Physiotherapy, Lad Krunal ${ }^{3}$, Bachelor of Physiotherapy, Ramani Krishna ${ }^{4}$, Bachelor of \\ Physiotherapy, Vadodariya Ruchi ${ }^{5}$, Bachelor of Physiotherapy}

${ }^{1}$ Lecturer, ${ }^{2}$ Associate Professor, ${ }^{3-5}$ Graduate Physiotherapists - The Sarvajanik College of Physiotherapy, Veer Narmad South Gujarat University, Surat, Gujarat, India

\section{ABSTRACT}

Background: Physiotherapists, despite having good knowledge of work related musculoskeletal disorders, are not immune to it. As literature related to these injuries in Physiotherapy profession in India is scarce, this study aims to investigate prevalence of work related musculoskeletal disorder, job risk factors commonly involved and coping strategies used among Physiotherapist in India.

Methods: A semi structured questionnaire adopted from questionnaires used for similar studies around the world was circulated to 314 Physiotherapists. A total of 271 questionnaires were received back with a response rate of $86 \%$. Mean, standard deviation, frequency, percentage and chi square test were used as appropriate for data analysis.

Results: Prevalence of work related musculoskeletal disorders was found to be $62.73 \%$. Lower back region was affected the most $(65.3 \%)$ followed by neck (41.8\%) and shoulder $(26.5 \%)$. As per response of therapists in this study, the most common risk factors were: working in static positions for longer periods (77\%), treating large number of patients in single day (68.2\%) and bending and twisting back in awkward positions (65.8\%).Common coping strategies adopted by respondents were: modifying positions of patient and self (54.1\%), adjusting height of treatment surface $(47.1 \%)$ and selection of techniques that does not aggravate or provoke discomfort $(41.8 \%)$. Conclusion: This study has identified the prevalence of work related musculoskeletal disorders among Physiotherapists in India and possible risk factors associated with this profession. It has also identified the common coping strategies utilized by therapists. These findings would be significant in modifying risk factors to prevent and/ or minimize work related musculoskeletal disorders among physiotherapists.

Key words: Coping strategies, Ergonomics, Indian Physiotherapists, Job risk factors, Work related musculoskeletal disorders

DOI: https://doi.org/10.3126/ijosh.v6i2.22526

\section{Introduction}

W ork related Musculoskeletal disorder (WRMD) are work related injuries that occur as a result of work procedures, working environment or equipment that are utilized at work place. WRMD among healthcare workers have been studied in the past with

\section{Corresponding Author}

Saravanan M

Associate Professor,

The Sarvajanik College of Physiotherapy

Badatwadi, Chhada-Ole, Rampura,

Surat - 395003, Gujarat, India

Mob: +919375985609

E-mail: saravananmurugan77@gmail.com more focus on nursing professionals [1-3], dentists [4-6] and surgeons [7] .

Physiotherapy as an occupation is physically demanding and involves therapists in bending, twisting, reaching or a combination of all positions. Awkward positioning while performing manual therapy techniques by Physiotherapists causes increased loads on spine making them susceptible to WRMD [8]. Owing to the increased level of patient contact, methods employed in the profession, application of manual techniques in practice and various other variables, WRMD are common in Physiotherapy practice $[9,10]$. Studies in the past have revealed that

(C) 2016 IJOSH All rights reserved 
91\% therapists experience WRMD during their career with a recurrence rate of $88 \%$. About $80 \%$ of therapists experienced symptoms in at least one body area over a 12 month period and 1 in 6 therapists changed their area of specialty as a result of WRMD [11, 12]. Despite various studies reporting a variance in the prevalence of WRMD among Physiotherapy population, there are few literatures on the prevalence of WRMD among Indian Physiotherapists [13]. Thus, the aim of this study is to estimate the prevalence of WRMD, to identify the potential job risk factors causing WRMD and to identify the possible coping mechanisms/strategies used commonly by Physiotherapists in India. Findings of this study would provide baseline data on the prevalence of WRMD among Physiotherapists in India which in turn would contribute to the body of knowledge. This would be helpful to identify possible job risk factors related to physiotherapy and coping strategies commonly adopted by Indian Physiotherapists.

\section{Methods}

A Cross sectional study was conducted by collecting details of all Physiotherapists working in Surat through Medical Directory for South Gujarat (Hello Doctor2013). Therapists who were involved in direct patient handling were included in the study. Therapists with only administrative responsibilities were excluded from the study. Informed consent was obtained from the participants before the commencement of the study by explaining the details of the study in accordance with the institutional ethical standards of the ethics committee on human experimentation and the Helsinki declaration of 1975 .

Data Collection involved a self - administered, semi - structured questionnaire consisting of 3 parts. The first part of the questionnaire collected demographic and profession related information of participants. This included the years of experience, work set up in which they were working, number of working hours per day, number of patients treated per day and specialty they belong to wherever applicable. It also included question on their knowledge of ergonomics and training in ergonomics. This part of the questionnaire also covered WRMD related symptoms in the past 12 months, part(s) of the body affected, onset of the symptoms and modifications done based on the symptoms.

The second part of the questionnaire included listing of
17 conditions and tasks based on previous published surveys [9, 14, 15], modified for use among Indian population. The respondents were instructed to indicate on a score of 1 to 4 , on how the 17 factors contributed to their WRMD. A score of 1 indicated irrelevant or no contribution, 2 indicated the factor contributed to WRMD in a minor or insignificant way, 3 moderately significant and 4 indicated major contributions of the factors. During analysis, responses of each factor were dichotomized into two categories: not a significant contributor (1 and 2) and significant contributor (3 and 4).

The final part of the questionnaire required the participants to choose the coping strategies commonly adopted by them from a list of nine coping methods. The coping strategies mentioned in this study was also adopted from previous published surveys [16]. They were instructed that the response to coping strategies should reflect what they actually do in practice rather than what they would like to do or think should do. Responses were graded as strategies used almost always, sometimes and almost never.

Questionnaires were hand delivered to 314 Physiotherapists from different corporation zones of Suratcity, Gujaratstate, India. The list of Physiotherapists was collected from the Medical Directory of South Gujarat. Apart from the list mentioned in the directory, Physiotherapists in direct contact were also included in this study, based on the inclusion criteria. They were asked to complete and return the questionnaire within a week. It was collected from their respective places by the researchers in person. A reminder was sent after a week if the questionnaires were not received back. Questionnaires were number coded to facilitate follow up on respondents.

Collected data were analyzed using SPSS v 20.0 with alpha level set at $p<0.05$. Descriptive statistics of mean, standard deviation for continuous variables and percentage (frequency) for categorical variables were used. Inferential statistics of Chi square analysis was used to determine the association between the presence of WRMD symptoms and certain demographic factors like age group, gender, Body Mass Index (BMI), experience of therapists, specialty of work, type of work setup, number of working hours per day, number of patients treated per day, type of specialty other than fitness, knowledge of ergonomics, ergonomics training. 


\section{Results}

A total of 271 questionnaires were returned out of 314 distributed questionnaires, with an overall response rate of $86 \%$. A total of $64.9 \%$ of respondents were in the age group of $21-25$ years and $28.8 \%$ of respondents belonged to the age group of 26-30 years. Female respondents $(72.3 \%)$ were higher as compared to their male counterparts $(27.7 \%)$. Frequency analysis of BMI category of respondents revealed $77.1 \%$ in normal category and $15.3 \%$ in overweight and obese category. Almost $75 \%$ of therapists had professional experience in the range of $1-5$ years, with $13.3 \%$ having less than 1 year and $11.8 \%$ more than 5 years. $68.6 \%$ worked in clinical setup, $38 \%$ were attached to hospitals and $55.7 \%$ treated patients through home visits. $69 \%$ of therapists were working 6-10 hours a day, $13.3 \%$ more than 10 hours and rest $17.7 \%$ less than 5 hours a day. On an average the working hours of therapists who participated in this study was 8 hours per day. $32.5 \%$ treated $11-20$ patients per day while $56.5 \%$ therapists treated less than 10 patients per day. $58.7 \%$ therapists had general practice, $42.1 \%$ focused only on patients with musculoskeletal disorders, $31 \%$ were practicing neurological physiotherapy, $21.4 \%$ were functioning as pediatric physiotherapists and $11.8 \%$ had fitness as their specialty.

Table 1 shows the detailed demographic data of respondents which were analyzed collectively and gender wise separately.

Out of 271 respondents, 170 complained of having WRMD symptoms in the past 12 months which contributed to overall prevalence of $62.7 \%$. It was found that female physiotherapists were affected more $(69 \%)$ than their male counterparts $(31 \%)$. Out of the ten anatomical regions specified in the questionnaire, low back $(65.3 \%)$ was identified to be the common region affected, followed by the neck $(41.8 \%)$ and shoulder (26.5\%) (Figure: 1).

Table 1: Overall \& Gender wise demographic characteristics of respondents

\begin{tabular}{lccc}
\hline Demographic Characteristics/Factors & $\begin{array}{c}\text { Mean (SD) } \\
\text { Overall }(\mathbf{n}=\mathbf{2 7 1})\end{array}$ & $\begin{array}{c}\text { Mean (SD) } \\
\text { Male }(\mathbf{n}=\mathbf{7 5})\end{array}$ & $\begin{array}{c}\text { Mean (SD) } \\
\text { Female }(\mathbf{n}=196)\end{array}$ \\
\hline Age (Years) & $25.38(3.20)$ & $26.95(3.27)$ & $24.79(2.97)$ \\
\hline Height $(\mathrm{cm})$ & $160.77(8.79)$ & $169.71(8.52)$ & $157.34(6.08)$ \\
\hline Weight $(\mathrm{kg})$ & $57.19(10.62)$ & $67.06(9.4)$ & $53.41(8.42)$ \\
BMI $\left(\mathrm{kg} / \mathrm{cm}^{2}\right)$ & $22.05(3.22)$ & $23.32(3.25)$ & $21.56(3.08)$ \\
Years of Physiotherapy Practice & $3.98(2.82)$ & $3.78(2.79)$ & $2.46(2.69)$ \\
Number of patients /day under direct care & $13.26(11.63)$ & $18.87(13.79)$ & $10.57(6.1)$ \\
Number of hours / day in direct patient care & $8.07(2.54)$ & $9.72(2.44)$ & $7.44(2.28)$ \\
\hline
\end{tabular}

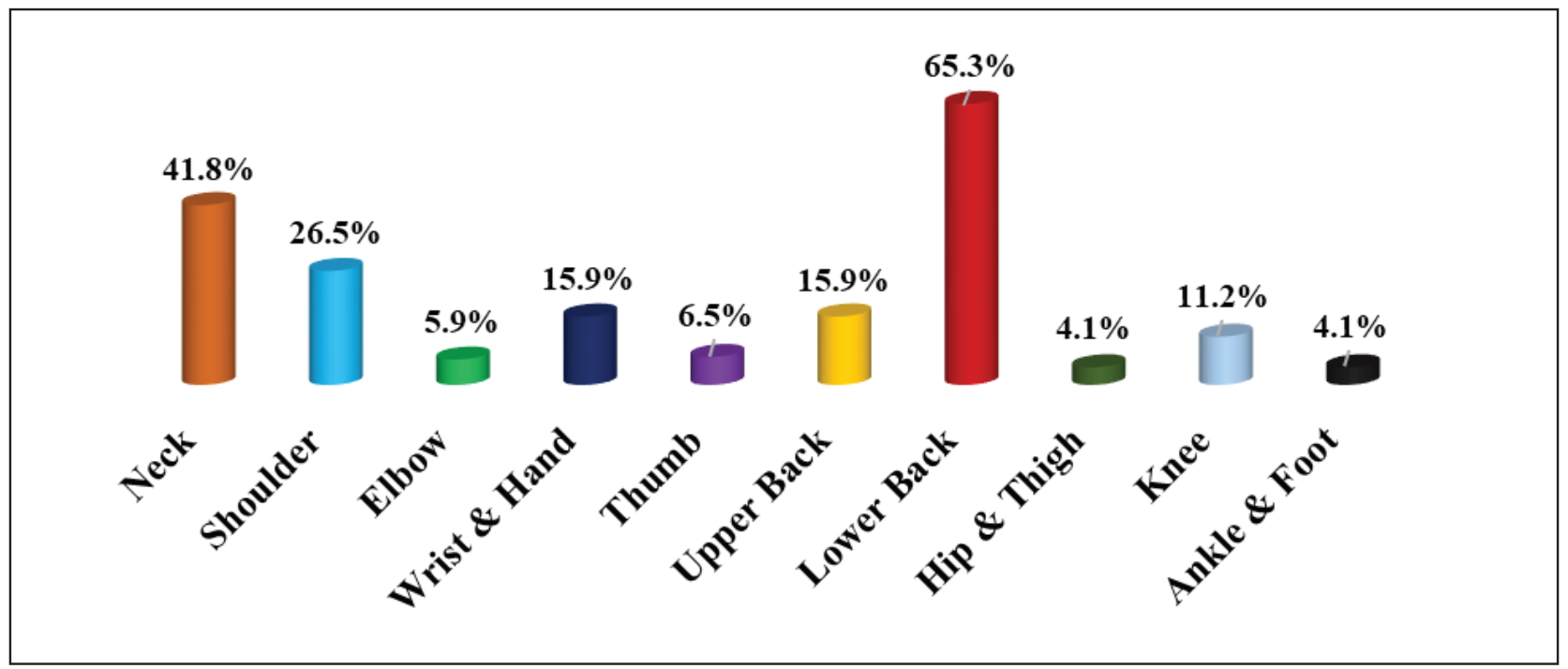

Figure 1: Distribution of Anatomical regions affected among Physiotherapists - Overall 
Table 2 represents the anatomical regions of the body affected in Physiotherapists as per gender. When analyzed separately based on gender, it was found that low back, neck and shoulder were commonly involved in females as compared to low back, neck and wrist and hand involvement in males.

Table 2: Anatomical regions affected among Physiotherapists - Gender wise

\begin{tabular}{lcc}
\hline $\begin{array}{l}\text { Anatomical region } \\
\text { affected }\end{array}$ & $\begin{array}{c}\mathbf{n}(\%) \text { Male } \\
(\mathbf{n = 5 3 )}\end{array}$ & $\begin{array}{c}\mathbf{n}(\%) \text { Female } \\
(\mathbf{n = 1 1 7 )}\end{array}$ \\
\hline Neck & $16(30.2)$ & $55(47)$ \\
Shoulder & $7(13.2)$ & $38(32.5)$ \\
Elbow & $2(3.8)$ & $8(6.8)$ \\
Wrist and hand & $8(15.1)$ & $19(16.2)$ \\
\hline Thumb & $0(0)$ & $11(9.4)$ \\
Upper Back & $6(11.3)$ & $21(17.9)$ \\
\hline Lower back & $36(67.9)$ & $75(64.1)$ \\
Hip and Thigh & $2(3.8)$ & $5(4.3)$ \\
Knee & $6(11.3)$ & $13(11.1)$ \\
Ankle and Foot & $2(3.8)$ & $5(4.3)$ \\
\hline
\end{tabular}

Duration of onset of WRMD among Physiotherapists was found to be $60 \%$ during the first five years of Physiotherapy practice (Figure 2), while only $4.1 \%$ experienced WRMD after 5 years of graduation. Gender wise analysis of onset of WRMD also showed similar response (Table 3).
Table 3: Onset duration of WRMD among Physiotherapists- Gender Wise

\begin{tabular}{lcc}
\hline Onset Duration & $\begin{array}{c}\mathbf{n}(\%) \text { Male } \\
(\mathbf{n = 5 3 )}\end{array}$ & $\begin{array}{c}\mathbf{n}(\%) \text { Female } \\
(\mathbf{n = 1 1 7 )}\end{array}$ \\
\hline Before PT & $6(11.3)$ & $5(4.3)$ \\
As PT student & $7(13.2)$ & $26(22.2)$ \\
1 $^{\text {st }}$ 5 Years & $34(64.2)$ & $68(58.1)$ \\
5-15 years & $2(3.8)$ & $5(4.3)$ \\
\hline
\end{tabular}

$97 \%$ of respondents revealed that they have knowledge of ergonomics and close to $60 \%$ respondents reported that they were trained in ergonomics. (Figure: 3 ).

Table 4 shows the commonly perceived risk factors identified by the participants in percentage. Multiple responses were obtained and percentages of significant contributor to WRMD are displayed. Prolonged static positions used during treatment $(77 \%)$, and number of patients handled per day (68.2\%) and bending ,twisting back in awkward positions while giving treatment to patients $(65.8 \%)$ were considered to be the most common risk factors as identified by the participants.

Modifying the patient's position self-position during treatment application is used commonly as a coping mechanism to overcome WRMD. Adjusting the height of the plinth accordingly has also been used as a coping strategy (Table 5).

Table 4: Job risk factors identified by Physiotherapists as common contributors to WRMD

\begin{tabular}{lc}
\hline Job Risk Factors & $\mathbf{n ~ ( \% )}$ \\
\hline Performing the same task over and over & $83(48.8)$ \\
\hline Treating a large number of patients in one day & $116(68.2)$ \\
\hline Not enough rest breaks during the day & $93(54.7)$ \\
\hline Performing manual orthopedic techniques (joint or soft tissue mobilization) & $69(40.6)$ \\
\hline Working in awkward or cramped positions & $108(63.6)$ \\
\hline Working in the same position for long periods (standing, bend over, sitting, etc) & $131(77.0)$ \\
\hline Bending or twisting back in an awkward way & $112(65.8)$ \\
\hline Reaching or working away from body & $90(53.0)$ \\
\hline Unanticipated sudden movement or falls by patient & $80(47.1)$ \\
\hline Assisting patient during gait activities & $69(40.6)$ \\
\hline Lifting or transferring dependent patients & $97(57.0)$ \\
\hline Working with confused or agitated patients & $63(37.0)$ \\
\hline Carrying, lifting or moving heavy materials or equipment & $80(47.1)$ \\
\hline Working at or near physical limits & $85(50.0)$ \\
\hline Continuing to work when injured or hurt & $108(63.6)$ \\
\hline Work scheduling (over time, irregular shift, length of workday) & $94(55.3)$ \\
\hline Inadequate training in injury prevention & $84(49.4)$ \\
\hline
\end{tabular}


Table 5: Coping strategies commonly used by Physiotherapists with WRMD

\begin{tabular}{lccc}
\hline Strategies & Always & Sometimes & Never \\
& $\mathbf{n}(\%)$ & $\mathbf{n}(\%)$ & $\mathbf{n}(\%)$ \\
\hline I get someone else to help me handle a heavy patient & $42(24.7)$ & $102(60)$ & $26(15.3)$ \\
\hline I modify patient's position/ my position & $92(54.1)$ & $71(41.8)$ & $7(4.1)$ \\
\hline I use a different part of my body to administer a manual technique & $66(38.8)$ & $73(42.9)$ & $31(18.2)$ \\
\hline I warm up and stretch before performing manual technique & $15(8.8)$ & $62(36.5)$ & $93(54.7)$ \\
\hline I use electrotherapy instead of manual techniques to avoid stressing an & $17(10.0)$ & $61(35.9)$ & $92(54.1)$ \\
injury & $46(27.1)$ & $93(54.7)$ & $31(18.2)$ \\
I pause regularly so I can stretch and change posture & $80(47.1)$ & $67(39.4)$ & $23(13.5)$ \\
\hline I adjust plinth/bed height before treating a patient & $71(41.8)$ & $79(46.5)$ & $20(11.8)$ \\
\hline I select techniques that will not aggravate or provoke my discomfort & $25(14.7)$ & $85(50.0)$ & $60(35.3)$ \\
\hline I stop a treatment if it causes or aggravate my discomfort & & & \\
\hline
\end{tabular}

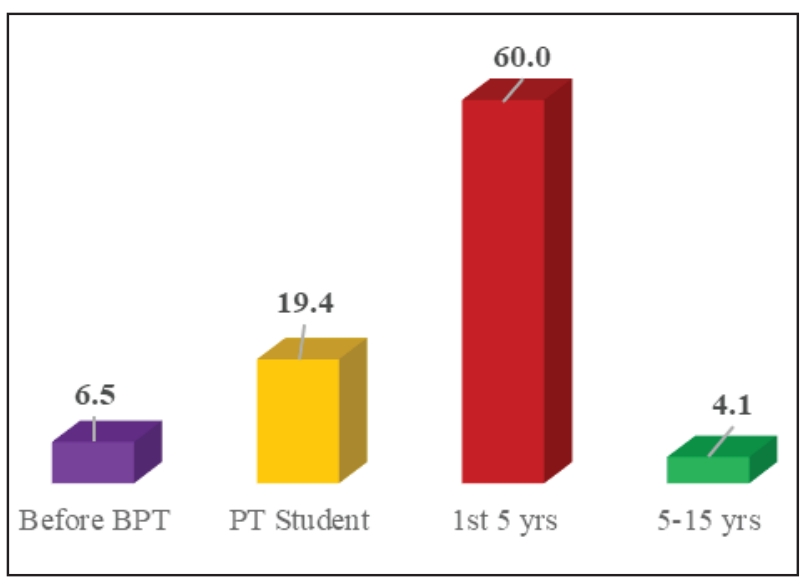

Figure 2: Onset duration of WRMD among Physiotherapists- Overall

The least adopted coping strategies observed wereperforming warm up and stretching before providing treatment to patients $(8.8 \%)$ and switching to electrotherapy modalities in place of manual therapy $(10 \%)$.

A strong association was observed between BMI and WRMD among the participating Physiotherapists, $x^{2}(3,9.091), p=0.028$ (Table 6). Similarly results of chi square analysis showed significant associations between fitness specialty and WRMD, $x^{2}(1,7.271)$, $\mathrm{p}=0.007$ (Table 7)

Table 6: Chi-Square test of BMI Vs WRMD

\begin{tabular}{lccc}
\hline & Value & Df & $\begin{array}{c}\text { Asymp. Sig. } \\
\text { (2-sided) }\end{array}$ \\
\hline Pearson Chi-Square & $9.091^{\mathrm{a}}$ & 3 & .028 \\
Likelihood Ratio & 9.174 & 3 & .027 \\
Linear-by-Linear & 5.584 & 1 & .018 \\
Association & 271 & & \\
N of Valid Cases & & & \\
\hline
\end{tabular}

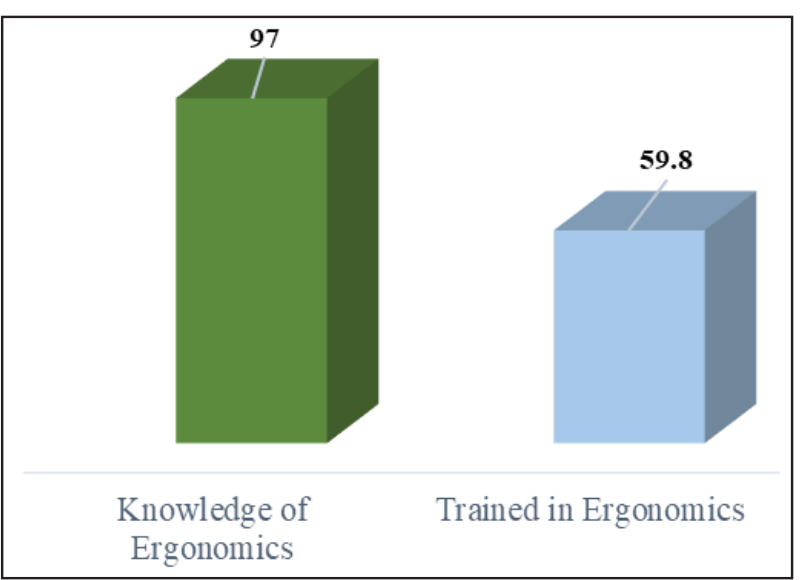

Figure 3: Percentage distribution of Physiotherapists with Ergonomic knowledge and training

Table 7: Chi-Square test of Fitness practice Vs WRMD

\begin{tabular}{lccc}
\hline & Value & Df & $\begin{array}{c}\text { Asymp. Sig. } \\
\text { (2-sided) }\end{array}$ \\
\hline Pearson Chi-Square & $7.271^{\mathrm{a}}$ & 1 & .007 \\
Likelihood Ratio & 6.259 & 1 & .012 \\
Linear-by-Linear & 8.164 & 1 & .004 \\
Association & & & \\
N of Valid Cases & & & \\
\hline
\end{tabular}

\section{DISCUSSION}

This study found higher prevalence of WRMD among practicing physiotherapist from Surat city. Response rate was $86 \%$ which was higher than any other previous studies conducted on Physiotherapists across the globe.

Prevalence of WRMD among Physiotherapists in our study showed $62.73 \%$ therapists reporting WRMD symptoms in the past 12 months. This prevalence rate is higher as compared to studies conducted among 
physiotherapists from California, lowa, Jeddah, Kuwait and Queensland [9, 17-20]. However, studies by Cromie J E [12], Adegoke O A [21], Nkhata L A [22], Salik $Y$ [23] found higher prevalence of WRMD among physiotherapists than the present study.

About $65.3 \%$ reported Low Back as the most common anatomical region of body affected due to WRMD, which was followed by neck and shoulder (Figure 2). Result of this study were consistent with findings from previous studies by Molumphy $M$ et al [17], Alroweyah $\mathrm{N} \mathrm{H}$ et al [20], Isabelle $\mathrm{C} \mathrm{N}$ et al [19], Nkhata L A et al [22], Salik Y \& Ozcan A [23], Bork et al [9], Adegoke O A et al [21], Holder N L et al [10], West D J et al [18], Glover et al [24] and Cromie J E et al [12]. WRMD in the wrist and hand, thumb when combined was $22.5 \%$ and this may reflect the less frequent application of manual therapy techniques in an Indian set up where therapists mostly rely on modality based management rather than on a hands on approach. Higher percentage of male physiotherapists complained of low back problem as compared to their female counterparts (Table 2). First episode of WRMD as reported by $60 \%$ respondents was during the first five years of practice. This can be attributed to lack of experience in handling techniques and enthusiasm to work harder at an entry level to treat patients.

Most important job risk factors identified by physiotherapists as a cause for WRMD in this study were working in the static positions, treating a large number of patients in a day, bending and twisting of back. These results were consistent with results of other studies [9, 10, 12, 17, 18, 22, 25]. Commonly adopted coping strategies for the prevention of WRMD were modifying positions of self or of patients, adjusting the treating surface (plinth, bed) prior to treatment and choice of techniques that does not provoke or aggravate their symptoms or discomfort. Only $8.8 \%$ of respondents reported warming up or stretching before performing manual therapy. Similarly despite $97 \%$ of respondents having knowledge in ergonomics and $60 \%$ trained in ergonomics, lack of application of stretching or warming up before performing a manual technique and absence of practical implication of ergonomic principles in the professional work place set up by Physiotherapists, are areas of concern which needs to be addressed.

Chi-Square statistics revealed statistically significant associations between BMI category and WRMD (Table 6), $X^{2}(3)=9.091, p=.028$; Fitness specialty and WRMD (Table 7), $X^{2}(1)=7.271, p=.007$. However, weak associations were observed between age group, gender, experience of therapists, type of work setup, number of working hours per day, number of patients treated per day, type of specialty other than fitness, knowledge of ergonomics, ergonomics training and WRMD.

\section{Conclusion}

Prevalence of WRMD among Physiotherapists from India was higher than most of the values reported from around the globe. Low back was the most affected anatomical region of the body. Static positions combined with bending \& twisting contributed more to WRMD as did treating large number of patients in a day. Since, eliminating these risk factors are least possible due to nature \& pattern of job involvement in Physiotherapy, there is a need to implement ergonomic modifications suitable to the work situation. Results of this study would help in planning prevention strategies, modifying risk factors causing WRMD and appropriate application of ergonomic changes in preventing WRMD among practicing Physiotherapists.

\section{References}

1. Alexopoulos EC, Burdorf A, Kalokerinou A: Risk factors for musculoskeletal disorders among nursing personnel in Greek hospitals. International archives of occupational and environmental health 2003, 76(4):289-294.

2. Lagerstrom $M$, Wenemark $M$, Hagberg $M$, Hjelm EW: Occupational and individual factors related to musculoskeletal symptoms in five body regions among Swedish nursing personnel. International archives of occupational and environmental health 1995, 68(1):27-35. DOI: https://doi.org/10.1007/
BF01831633. Jane Lipscomb AT, Barbara Brady, Jeanne Geiger-Brown: Health Care System Changes and Reported Musculoskeletal Disorders Among Registered Nurses. American journal of public health 2004, 94(8):1431-1435. DOI: https:// doi.org/10.2105/AJPH.94.8.1431

4. Finsen L, Christensen H, Bakke M: Musculoskeletal disorders among dentists and variation in dental work. Applied ergonomics 1998, 29(2):119-125. DOI: https://doi.org/10.1016/S0003-6870(97)000173

5. Finsen L, Christensen H: A biomechanical study of occupational loads in the shoulder and elbow 
in dentistry. Clinical biomechanics 1998, 13(45):272-279. DOI: https://doi.org/10.1016/S02680033(98)00096-5

6. Alexopoulos EC, Stathi IC, Charizani F: Prevalence of musculoskeletal disorders in dentists. BMC musculoskeletal disorders 2004, 5:16. DOI: https:// doi.org/10.1186/1471-2474-5-16

7. Grace P. Y. Szeto PH, Albert C. W. Ting, Jensen T. C. Poon, Stephen W. K. Cheng, Raymond C. C. Tsang: Work-related Musculoskeletal Symptoms in Surgeons. Journal of Occupational Rehabilitation 2004, 19(2):175-184.

8. Campo M, Weiser S, Koenig KL, Nordin M: Workrelated musculoskeletal disorders in physical therapists: a prospective cohort study with 1-year follow-up. Physical therapy 2008, 88(5):608-619. DOI: https://doi.org/10.2522/ptj.20070127

9. Bork BE, Cook TM, Rosecrance JC, Engelhardt KA, Thomason ME, Wauford IJ, Worley RK: Workrelated musculoskeletal disorders among physical therapists. Physical therapy 1996, 76(8):827-835. DOI: https://doi.org/10.1093/ptj/76.8.827

10. Nicole $L$ Holder HAC, John M DiBlasio, Carol $L$ Hughes, John W Scherpf, Linn Harding, Katherine F Shepard: Cause, Prevalence, and Response to Occupational Musculoskeletal Injuries Reported by Physical Therapists and Physical Therapist Assistants. Physical therapy 1999, 79(7):642-652. DOI: https://doi.org/10.1093/ptj/79.7.642

11. Cromie JE, Robertson VJ, Best MO: Occupational injuries in PTs. Physical therapy 2000, 80(5):529530.

12. Cromie JE, Robertson VJ, Best MO: Work-related musculoskeletal disorders in physical therapists: prevalence, severity, risks, and responses. Physical therapy 2000, 80(4):336-351. DOI: https://doi. org/10.1093/ptj/80.4.336

13. Buddhadev Neeti P KIS: Work Related Musculoskeletal Disorders: A Survey of Physiotherapists in Saurashtra Region. National Journal of Medical Research 2012, 2(2):179-181.

14. Lotters F, Burdorf A, Kuiper J, Miedema H: Model for the work-relatedness of low-back pain. Scandinavian journal of work, environment \& health 2003, 29(6):431-440. DOI: https://doi.org/10.5271/ sjweh.749

15. Palmer KT, Smedley J: Work relatedness of chronic neck pain with physical findings--a systematic review. Scandinavian journal of work, environment
\& health 2007, 33(3):165-191. DOI: https://doi. org/10.5271/sjweh.1134

16. Adegoke BO, Akodu AK, Oyeyemi AL: Workrelated musculoskeletal disorders among Nigerian physiotherapists. BMC musculoskeletal disorders 2008, 9:112. DOI: https://doi.org/10.1186/1471 2474-9-112

17. Molumphy M, Unger B, Jensen GM, Lopopolo RB: Incidence of work-related low back pain in physical therapists. Physical therapy 1985, 65(4):482-486. DOI: https://doi.org/10.1093/ptj/65.4.482

18. West DJ GD: Occupational injuries of physiotherapists in North and Central Queensland. Aust J Physiother 2001, 47:179-186. DOI: https:// doi.org/10.1016/S0004-9514(14)60265-8

19. Isabelle C.N. Devreux BA-A, Khaled Mamdouh, Enas Elsayed: Relation of Work-related Musculoskeletal Disorders and Over-commitment of Rehabilitation Staff in Saudi Arabia. Life Science Journal 2012, 9(3):781-785.

20. Alrowayeh HN, Alshatti TA, Aljadi SH, Fares $\mathrm{M}$, Alshamire MM, Alwazan SS: Prevalence, characteristics, and impacts of work-related musculoskeletal disorders: a survey among physical therapists in the State of Kuwait. BMC musculoskeletal disorders 2010, 11:116. DOI: https://doi.org/10.1186/1471-2474-11-116

21. Babatunde OA Adegoke AKA, Adewale L Oyeyemi: Work-related musculoskeletal disorders among Nigerian Physiotherapists. BMC musculoskeletal disorders 2008, 9(112):1-9.

22. L.A. Nkhata CZ, S.H. Nzala, S. Siziya: Work-related Musculoskeletal Disorders: prevalence, contributing factors and coping strategies among Physiotherapy personnel in Lusaka, Kitwe and Ndola districts, Zambia. Medical Journal of Zambia 2010, 37(4):262267.

23. Salik Y, Ozcan A: Work-related musculoskeletal disorders: a survey of physical therapists in IzmirTurkey. BMC musculoskeletal disorders 2004, 5:27. DOI: https://doi.org/10.1186/1471-2474-5-27

24. Glover W MA, Sullivan C, Hague J. : Work-related musculoskeletal disorders affecting members of the Chartered Society of Physiotherapy. Physiotherapy 2005, 91:138-147. DOI: https://doi.org/10.1016/j. physio.2005.06.001

25. Scholey MMH: Back Pain In Physiotherapists Involved In Back Care Education. Ergonomics 1989, 32:179-190. DOI: https://doi. org/10.1080/00140138908966078 